\title{
Fitzpatrick Skin Type IV
}

National Cancer Institute

\section{Source}

National Cancer Institute. Fitzpatrick Skin Type IV. NCI Thesaurus. Code C74572.

Skin which is light brown and it rarely burns when exposed to the sun. It is usually seen in people of Mediterranean origin. 